\title{
SOME CONTACT RECTIFIERS OF ELECTRIC CURRENTS.
}

\section{By L. W. Austin.}

In a recent number of the Physical Review ${ }^{1}$ I have described an aluminum-tellurium contact capable of transforming small alternating currents of any frequency into direct currents by means of what seems to be thermoelectric action. It is not generally known, however, that there is a large number of solid conductors ${ }^{2}$ of electricity, metallic and nonmetallic, in which, when brought together so as to form a contact of not too low resistance, electricity appears to pass more easily in one direction than in the other.

Most cases of this kind are too uncertain and capricious in their action to allow definite study. But silicon in contact with almost any of the ordinary metals, carbon-steel, and tellurium-aluminum all show a well marked and fairly regular unilateral conductivity.

In the investigation of these contacts I have used two main

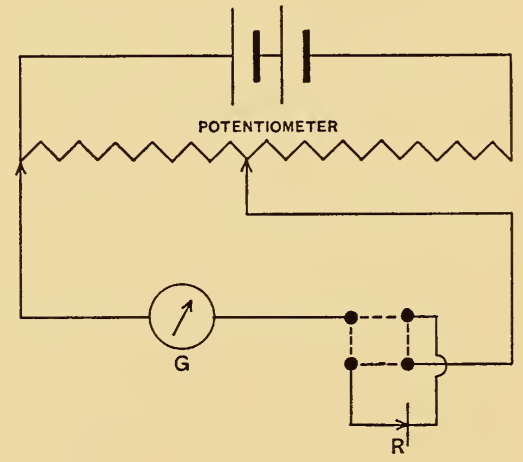

Fig. 1. methods of experiment. In the first, Fig. I, a direct electromotive force was applied to the contact $\mathrm{R}$, first in one direction and then in the other, and the resulting currents measured on a galvanometer or ammeter having resistances small in comparison

\footnotetext{
${ }^{1}$ Physical Review, 24, p. 508; 1907.

${ }^{2}$ Possibly the case of carborundum investigated by G. W. Pierce (Phys. Rev., 25, p. 31 ; 1907) may be a case of contact rectification.
} 
with that of the contact. In the second method, Fig. 2, a known alternating current at 60 cycles was sent through a fall of potential wire and the required voltages taken from sliding contacts and applied to the rectifying contact $R$, which was in series with the direct current meter.

\section{SILICON}

The fact that a piece of silicon when properly brought in contact with brass or copper, or, in fact, almost any of the common metals, is capable of acting as a detector for electrical oscillations without the use of external electromotive force was first announced by G. W. Pickard ${ }^{3}$ who, as it seems to me, erroneously ascribed the phenomenon to thermoelectric action. For while it is possi-

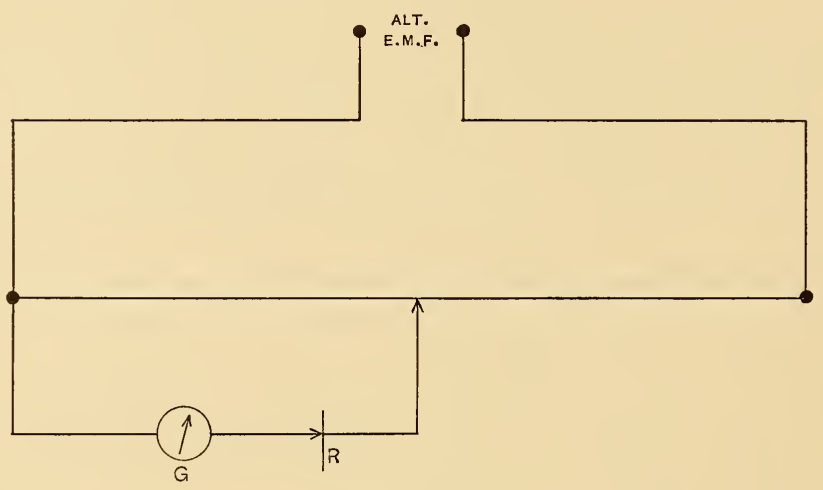

Fig. 2.

ble with much difficulty to adjust the contact so that for small electromotive forces the rectified current flows in the same direction as that produced by a heating of the junction, under ordinary conditions it flows in the opposite direction and may be far greater than could be produced by heating the junction to the melting point of the copper.

The rectifiers used in the experiments were made by embedding a piece of silicon $\mathrm{A}$ in solder ${ }^{4}$, Fig. 3, and bringing a bit of brass or steel wire $\mathrm{P}$ soldered to the end of a flat spring $\mathrm{S}$ in contact with it. The contact pressure is adjusted by means of a screw M pressing on the spring from above. As some points on

\footnotetext{
${ }^{3}$ Electrical World, 48, p. 1003 ; 1906.

${ }^{4}$ It is often of advantage to polish the contact surface of the rough silicon on an oil stone.
} 
the silicon are far more sensitive than others, the contact point is also made adjustable.

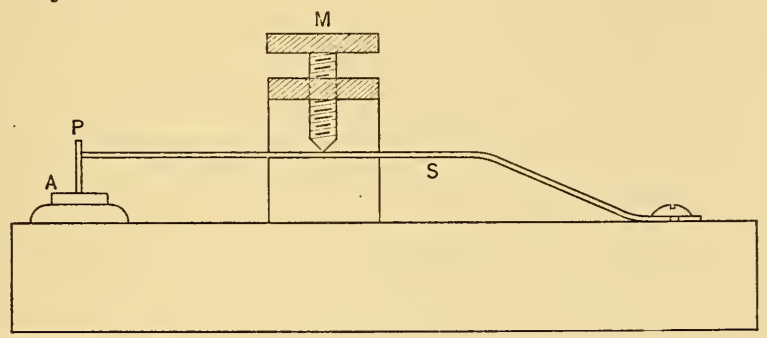

Fig. 3.

Table I shows the unilateral conductivity of a silicon-steel contact for direct currents. The arrangement of the circuit is that TABLE I.

Silicon-Steel. (Direct Current.)

\begin{tabular}{|c|c|c|c|c|c|c|}
\hline & & Silicon & Steel & Steel to & ilicon & \\
\hline Vo & olts & 0 & Apparent & $\mathrm{C}$ & Apparent & $\begin{array}{l}\text { Difference } 10^{-5} \\
\text { Amp. }\end{array}$ \\
\hline 0.014 & Galva- & 5.5 & 2600 & 5.8 & 2400 & 0.3 \\
\hline 0.028 & $\left\{\begin{array}{l}\text { nome- } \\
\text { ter }\end{array}\right.$ & 10.7 & 2600 & 11.9 & 2350 & 1.2 \\
\hline 0.042 & ohms. & 16 & 2600 & 18.5 & 2250 & 2.5 \\
\hline 0.070 & $\begin{array}{l}\text { Galva- } \\
\text { nome- }\end{array}$ & $3 \%$ & 2180 & 47 & 1490 & 15 \\
\hline 0.098 & ter & 45 & 2180 & 70 & 1400 & 25 \\
\hline 0.14 & $\int$ shunt. & 65 & 2150 & 118 & 1190 & 53 \\
\hline 0.28 & Galva- & 180 & 1550 & 600 & 467 & 420 \\
\hline 0.42 & ter & 300 & 1400 & 1250 & 336 & 950 \\
\hline 0.56 & shunt. & 400 & 1400 & 2200 & 254 & 1800 \\
\hline 0.70 & & 500 & 1400 & 2900 & 241 & 2400 \\
\hline 0.98 & & 800 & 1220 & 5000 & 196 & 4200 \\
\hline 1.4 & Milli- & 1200 & 1170 & 10000 & 140 & 8800 \\
\hline 1.7 & $\operatorname{cor}_{\text {ter }}$ & 2500 & 680 & 12800 & 133 & 10300 \\
\hline 2.0 & ohm. & 3200 & 625 & 16000 & 125 & 12800 \\
\hline 2.2 & & 4800 & 460 & 20000 & 110 & 15200 \\
\hline 2.5 & & 6000 & 420 & $\begin{array}{c}25000 \\
\text { (Unsteady) }\end{array}$ & 100 & 19000 \\
\hline
\end{tabular}

shown in Fig. I. The galvanometer $\mathrm{G}$ was a pointer instrument having a sensibility of $2 \times 10^{-6}$ ampere. The milliammeter used in 
place of the galvanometer for the larger currents had a sensibility of $\mathrm{I} \times \mathrm{IO}^{-3}$ ampere per division. This contact was used with the adjustment found most sensitive for small alternating currents. It is seen from the table that the resistance for currents in the direction steel to silicon drops rapidly with increasing voltage. Hence it is desirable to use galvanometers of low resistance with the higher voltages.

Table II contains the rectified currents for various alternating voltages, the contact being adjusted for maximum rectification TABLE II.

Silicon-Steel. (Alternating Current.)

$\left.\begin{array}{l|c}\hline \multicolumn{1}{c|}{\text { Volts A. C. }} & \text { Rectified Current }{ }^{-6} \text { Amp. } \\ \hline 0.02 \\ 0.04 \\ 0.055 \\ 0.065 \\ 0.090 \\ 0.11 \\ 0.13 \\ 0.13 \\ 0.15 \\ 0.185 \\ 0.22 \\ 0.25\end{array}\right\} \begin{gathered}\text { Galvanometer (280 ohms). } \\ 0.25 \\ 0.32 \\ 0.395 \\ 0.495\end{gathered}$

with the smaller voltages. ${ }^{5}$ It is to be noticed that these rectified currents up to about I.O volt correspond with some degree of approximation with the differences in the direct currents in Table I.

${ }^{5} \mathrm{~A}$ closer contact gives larger rectified currents for the larger voltages. 
Below 0.2 volt the phenomenon is extremely reproducible, and contacts may be set and remain constant in their action for weeks at a time, unless violently jarred or exposed to too high voltages. Within this range the rectified currents are approximately proportional to the square of the alternating voltage. Hence a silicon rectifier with a galvanometer is a useful instrument for all kinds of high frequency work with small currents. The effect for larger voltages, at least with the present form of contact, is more or less irregular, which is probably due to excessive heating.

In Table III and curve A of Fig. 4 are shown the relations between very small voltages and rectified current. The galvanometer used was of the ordinary D'Arsonval type, having a resistance of about $250 \mathrm{ohms}$ and a sensibility of $2 \times 1 \mathrm{IO}^{-8}$ ampere per division.

TABLE III.

Silicon-Steel. (Alternating Current.)

GALVANOMETER (250 OHMS).

\begin{tabular}{c|c|c}
\hline & \multicolumn{2}{|c}{ Rectified Current ro $^{-8}$ Amp. } \\
\cline { 2 - 3 } Volts A. C. & Obs. & Cal. \\
\hline 0.0014 & 0.6 & 0.4 \\
0.0028 & 1.7 & 1.6 \\
0.0042 & 4.1 & 3.7 \\
0.0056 & 7.6 & 6.6 \\
0.0070 & 10.7 & 10.3 \\
0.0098 & 20.3 & 20.2 \\
0.0140 & 39.2 & 41.2 \\
0.021 & 82.0 & 92.8 \\
0.025 & 107.0 & 131.0 \\
0.028 & 146.0 & 165.0 \\
0.042 & 312.0 & 371.0 \\
0.056 & 552.0 & 659.0 \\
\hline
\end{tabular}

For these very small voltages the direct current is apparently strictly proportional to the square of the voltage within the errors of observation, provided all the resistances in series with the rectifier are negligible. That this is not the case in Table III can be seen if the values calculated from the square law be compared 
with those observed. These values are given in the third column. In Table IV is given a similar set of observations, taken with the same galvanometer shunted to one-tenth. Here the errors in the agreement lie within the limits of the errors of observation. It is to be noted that for high frequency work the alternating

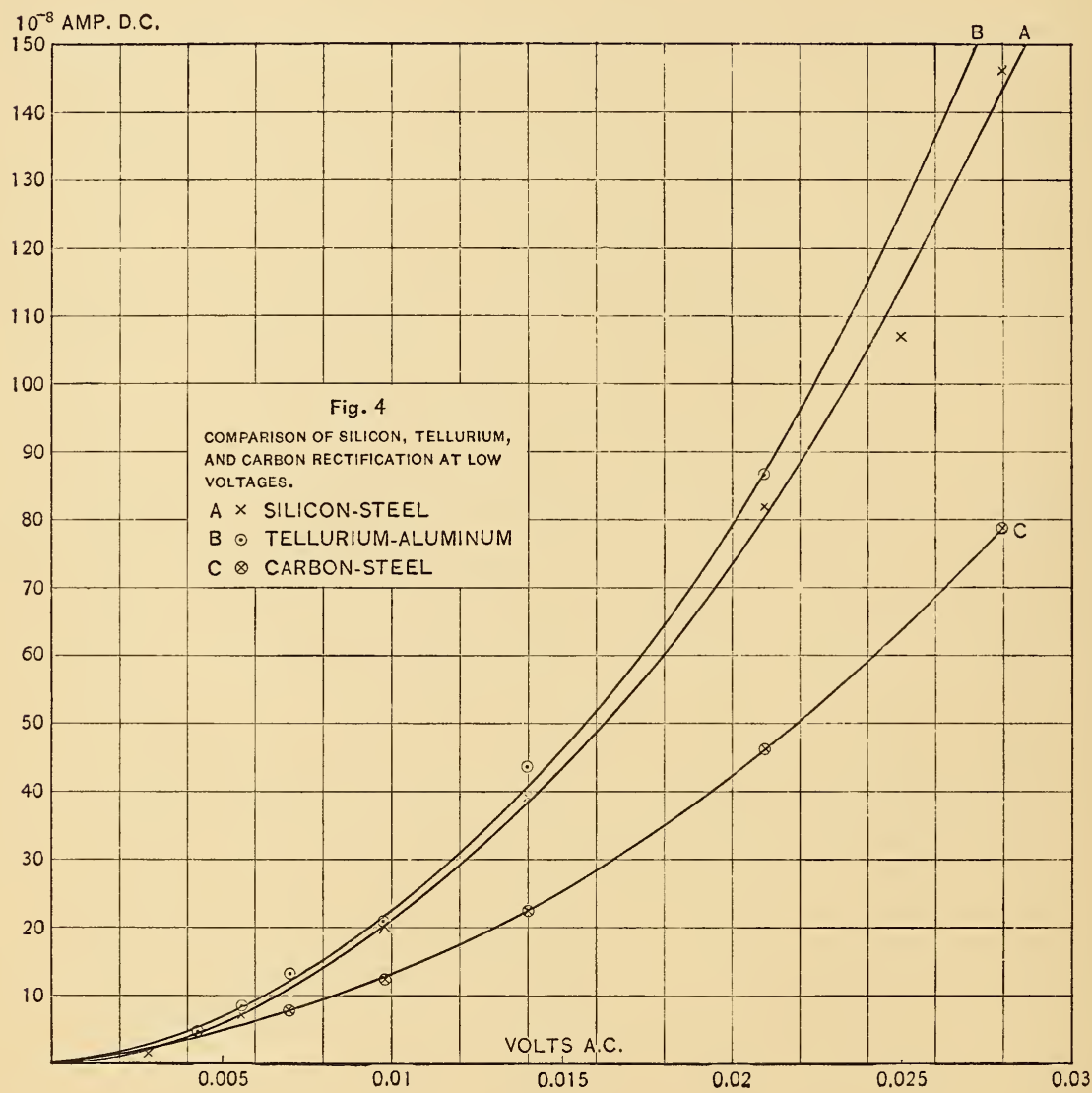

Fig. 4.

current does not pass through the galvanometer, and hence the square law may be generally taken as true.

With this same rectifier and galvanometer, observations were made, also, with high frequency currents and a comparison of sensitiveness made with the Wollaston wire electrolytic receiver connected to a pair of $200 \mathrm{ohm}$ telephone receivers of the type 
ordinarily used in wireless telegraphy. Even with this comparatively nonsensitive galvanometer, all signals of not too short duration capable of being distinctly heard in the telephones produced a readable deflection.

\section{TABLE IV.}

Silicon-Steel. (Alternating Current.)

GALVANOMETER (250 OHMS I/IO SHUNT).

\begin{tabular}{c|c|c}
\hline & \multicolumn{2}{|c}{ Rectified Current 10 $^{-8}$ Amp. } \\
\cline { 2 - 3 } Volts A. C. & Obs. & Cal. \\
\hline 0.0042 & 7.0 & 7.0 \\
0.0070 & 19.0 & 19.5 \\
0.0098 & 39.0 & 38.3 \\
0.014 & 77.0 & 78.2 \\
0.021 & 170.0 & 176.0 \\
0.028 & 311.0 & 312.0 \\
0.042 & 690.0 & 705.0 \\
0.056 & 1250.0 & 1250.0 \\
0.070 & 1960.0 & 1955.0 \\
\hline
\end{tabular}

For the determination of the absolute sensitiveness of the silicon rectifier at high frequencies, a rectifier of rather low sensibility was compared with an extremely sensitive thermoelement at a frequency of 140,000 . They were connected, in turn, in series with a one microfarad paper condenser for stopping the direct current, and with an inductance of 0.033 I microhenry coupled very loosely to a second tuned circuit in which oscillations were excited. The damping of the latter circuit was very small compared with that of the former. The readings on the galvanometer with the thermoelement indicated a mean alternating electromotive force for nine sets of observations, after taking account of the reactance of the coupling coil, of 0.0336 volt. The deflection due to the silicon indicated a mean electromotive force of 0.0350 volt, according to the calibration of the rectifier for low frequency currents. This discrepancy of 4 per cent is less than the average deviation from the mean $(5.2$ per cent). The experiment shows 
that there is no change in sensitiveness with frequency within the limits of accuracy of the observations. ${ }^{6}$

While in general the rectified current with silicon rectifiers flows from steel to silicon, an exception has been found in a certain sample which is probably somewhat less pure in its composition than the rest of the silicon specimens used. From this sample, rectifiers of exceptional sensitiveness have been made, but, curiously enough, the rectified current flows from silicon to steel, or in the opposite direction to that usually observed. Still more curiously, however, it is found that the thermoelectric electromotive force ${ }^{7}$ at the contact is also reversed, still remaining in opposition to the rectification. That this effect is really a property of this sample is shown by the fact that the reversals persist in the case of other pieces broken from the larger sample and also with freshly broken surfaces. As might be expected, when a contact is made between two specimens of silicon with the opposite rectifying qualities, a rectifier of remarkable sensitiveness is produced.

\section{CARBON-STEEL.}

Another substance capable of forming rectifying contacts is carbon. It gives the most satisfactory results when used with steel. ${ }^{8} \quad$ The rectifiers were made up in the same general form as those already described, the polished surface of an ordinary steel sewing needle in contact with arc light carbon ${ }^{9}$ giving excellent results. By varying the pressure it is possible to produce rectifiers of widely varying resistance.

For high resistance rectifiers particularly good results were obtained by making the contact on the soft center of a cored carbon. The high resistance contacts, while showing regular rectification for alternating currents, do not, so far as I have observed, show regular and satisfactory unilateral conductivity for direct currents.

\footnotetext{
${ }^{6}$ In using low frequency calibration for the measurement of high frequency currents, the contact must be close enough so that there is no tendency to coherer action.

7 The contact was heated by heating the wire above it in a small flame.

${ }^{8} \mathrm{~A}$ rectifier of some sensitiveness can be produced by bringing a bit of carbon incandescent light filament in contact with arc light carbon.

${ }^{9}$ Graphite seems to be distinctly inferior.
} 
Tables V and VI contain observations on a low resistance rectifier for direct and alternating currents. The differences in the direct currents correspond very closely with the rectified portion of the alternating current up to about 0.3 volt.

\section{TABLE V.}

Carbon-Steel. (Direct Current.)

MILLIAMMETER (0.3 OHM).

\begin{tabular}{|c|c|c|c|c|c|}
\hline \multirow[b]{2}{*}{ Volts } & \multicolumn{2}{|c|}{ Carbon to steel } & \multicolumn{2}{|c|}{ Steel to Carbon } & \multirow{2}{*}{$\begin{array}{l}\text { Current } \\
\text { Difference } \\
\text { 10 } 0^{-3} \text { Amp. }\end{array}$} \\
\hline & $\begin{array}{l}\text { Current } \\
{ }_{10}^{-3} \mathrm{Amp} \text {. }\end{array}$ & $\begin{array}{l}\text { Apparent } \\
\text { Resistance } \\
\text { Ohms }\end{array}$ & $\begin{array}{l}\text { Current } \\
\text { Io }^{-3} \mathrm{Amp} \text {. }\end{array}$ & $\begin{array}{l}\text { Apparent } \\
\text { Resistance } \\
\text { Ohms }\end{array}$ & \\
\hline 0.02 & 1.2 & 16.6 & 1.3 & 15.4 & 0.1 \\
\hline 0.05 & 3.1 & 16.1 & 3.4 & 14.7 & 0.3 \\
\hline 0.10 & 6.3 & 15.9 & 7.4 & 13.5 & 1.1 \\
\hline 0.20 & 13.0 & 15.4 & 15.1 & 13.2 & 2.1 \\
\hline 0.30 & 20.0 & 15.0 & 24.0 & 12.5 & 4.0 \\
\hline 0.40 & 33.0 & 12.1 & 40.0 & 10.0 & 7.0 \\
\hline
\end{tabular}

TABLE VI.

Carbon-Steel. (Alternating Current.)

GALVANOMETER (I OHM).

\begin{tabular}{c|c}
\hline Volts A. C. & Rectified Current ro $^{-3}$ Amp. \\
\hline 0.02 & 0.08 \\
0.03 & 0.15 \\
0.05 & 0.40 \\
0.10 & 1.0 \\
0.20 & 2.4 \\
0.30 & 3.8 \\
0.40 & 5.0 \\
\hline
\end{tabular}

A comparison with the silicon observations shows that for the higher voltages the carbon rectification is much less perfect, but as the carbon sensibility curve drops more slowly the difference for very small voltages is less. It is also to be noted that in the case of carbon the effect becomes too irregular for observation at a much lower voltage. 
Table VII shows the rectification of a high resistance rectifier for medium voltages, while Table VIII shows the same rectifier used with a more sensitive galvanometer for very low voltages. These results are shown also in curve $\mathrm{C}$ in Fig. 4.

TABLE VII.

Carbon-Steel. (Alternating Current.)

GALVANOMETER (280 OHMS).

\begin{tabular}{c|c}
\hline Volts A. C. & Rectified Current ${ }^{\text {Io-6 }}$ Amp. \\
\hline 0.02 & 0.4 \\
0.04 & 1.3 \\
0.06 & 2.2 \\
0.08 & 3.2 \\
0.10 & 4.9 \\
0.12 & 6.9 \\
0.14 & 9.0 \\
0.16 & 12.5 \\
0.18 & 15.5 \\
0.20 & 17.8 \\
0.21 & 20.0 \\
\hline
\end{tabular}

TABLE VIII.

Carbon-Steel. (Alternating Current.)

GALVANOMETER (250 OHMS).

\begin{tabular}{c|c}
\hline Volts A. C. & Rectified Current ro $^{-8}$ Amp. \\
\hline 0.0014 & 0.8 \\
0.0028 & 2.0 \\
0.0042 & 3.2 \\
0.0070 & 7.6 \\
0.0098 & 12.2 \\
0.014 & 22.2 \\
0.021 & 46.0 \\
0.028 & 78.6 \\
0.042 & 172.6 \\
0.056 & 290.0 \\
0.070 & 430.0 \\
\hline
\end{tabular}


TELLURIUM.

In addition to the rectifying effect of tellurium-aluminum contacts described in the paper already cited, which appears to be thermoelectric or at least in the same direction as the thermoelectric action and which becomes irregular above low voltages, there is a second rectifying effect in opposition to the first. This in general becomes prominent only at the higher voltages. There is a middle region in the vicinity of 0.5 volt where the two effects appear to be in conflict, and it is interesting as the alternating current is increased to see the galvanometer deflection change sign as one effect passes into the other. This second effect seems entirely analogous to the rectification of silicon and is of the same order of magnitude. Table IX and curve B of Fig. 4 show the action of tellurium-aluminum rectifiers for very small alternating

TABLE IX.

Tellurium-Aluminum. (Alternating Current.)

GALVANOMETER (250 OHMS).

\begin{tabular}{c|c}
\hline Volts A. C. & Rectified Current Io $^{-8}$ Amp. \\
\hline 0.0028 & 1.8 \\
0.0042 & 4.6 \\
0.0056 & 8.5 \\
0.0070 & 13.8 \\
0.0098 & 21.0 \\
0.014 & 44.0 \\
0.021 & 87.0 \\
0.028 & 160.0 \\
0.042 & 368.0 \\
0.056 & 690.0 \\
\hline
\end{tabular}

voltages at 60 cycles, and correspond fully to the silicon and carbon observations in Tables III and VIII. It is seen that the sensitiveness is almost exactly the same at that of the silicon-steel contact. For quantitative observations the tellurium-aluminum is somewhat inferior in point of constancy. In Table IX the rectified current is in the same direction as the thermoelectric 
current due to heating the contact. The curve of Fig. 5 shows the course of the phenomenon at somewhat higher voltages and the reversal of current as it passes into the opposite rectifying effect. The voltage at which this transition takes place depends on the pressure between the two metals at the contact, being lower the greater the pressure.

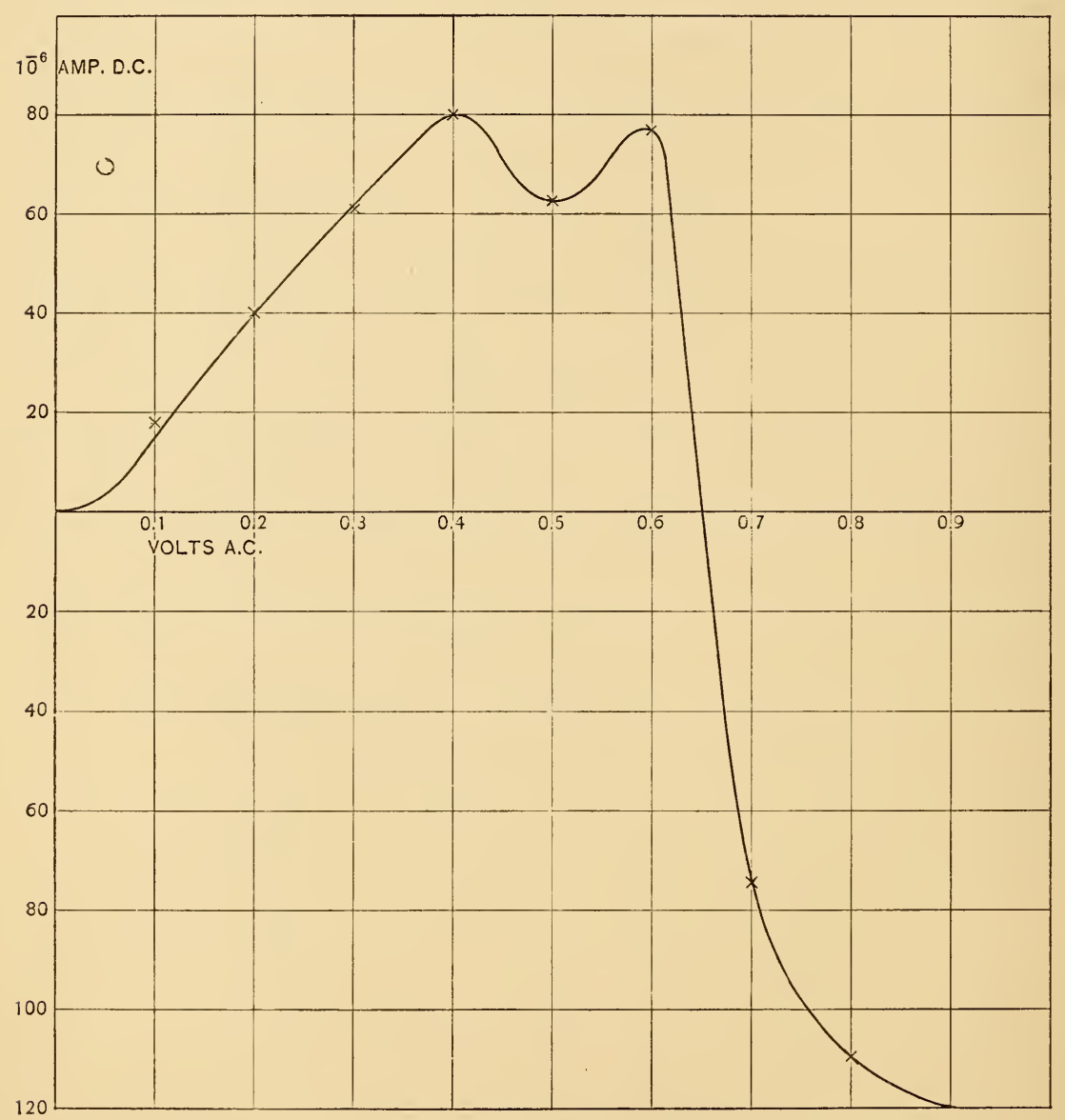

Fig. 5.

Table $\mathrm{X}$ shows the relation between alternating current voltage at 60 cycles and rectified current as measured on a milliammeter. In this case the contact was close and regulated to give a maximum effect at these voltages. Experiments have been made also on 
a contact formed by melting the end of a No. 20 aluminum wire into a block of tellurium, the other contact being formed by inserting a piece of white hot platinum wire in the tellurium. Hot

TABLE X.

Tellurium-Aluminum. (Alternating Current, close contact.)

\begin{tabular}{c|c}
\hline Volts A. C. & Rectified Current ${ }^{-3}$ Amp. \\
\hline 0.42 & \\
0.52 & 1 \\
0.63 & 2 \\
0.70 & 3 \\
0.98 & 5 \\
1.32 & 10 \\
& 20 \\
\hline
\end{tabular}

TABLE XI.

Tellurium-Aluminum. (Direct Current.)

\begin{tabular}{l|c|c|c|c}
\hline & \multicolumn{3}{|c|}{ Te to Al } & \multicolumn{2}{c}{ Al to Te } \\
\hline Volts & Amp. & $\begin{array}{c}\text { Apparent } \\
\text { Resistance } \\
\text { Ohms }\end{array}$ & Amp. & $\begin{array}{c}\text { Apparent } \\
\text { Resistance } \\
\text { Ohms }\end{array}$ \\
\hline 0.4 & 0.05 & 8.0 & 0.008 & 50 \\
0.6 & 0.10 & 6.0 & 0.008 & 75 \\
0.8 & 0.18 & 4.4 & 0.009 & 89 \\
1.0 & 0.25 & 4.0 & 0.010 & 100 \\
1.4 & 0.37 & 3.8 & 0.010 & 140 \\
2.8 & 1.00 & 2.8 & 0.015 & 186 \\
\hline
\end{tabular}

platinum inserted in this way forms a very low resistance contact, and in fact seems to become alloyed with the tellurium. A tellurium-aluminum contact of this kind, while it is not very efficient in rectifying alternating currents, apparently on account of slowness in action, has remarkable unilateral conductivity for direct currents, as is seen in Table XI, and has the additional advantage for purposes of investigation that all the conditions can be kept constant indefinitely. With this form of contact evidences of 
polarization have been sought by throwing the rectifier from the battery circuit into that of a galvanometer by means of a rapid commutator. If polarization exists, however, it is masked thus far by the large thermoelectric currents due to the unavoidable heating of the rectifying contact.

\section{CONCLUSIONS.}

There seems to be no obvious explanation of the phenomenon described above. I will therefore in conclusion only call attention to some of its more general characteristics.

In all the cases noticed, the contact has a resistance of several ohms as though there were a resisting film between the conductors. In all the cases, too, there is a comparatively poor conductor in contact with a good conductor, but the rectification in the cases of carbon-steel and of silicon-steel is from the good to the poor, while in tellurium-aluminum it is in the opposite direction (except for very low voltages where another phenomenon, perhaps thermoelectric, predominates). It may be worth noting that the first effect is in the same direction as the rectified current in the aluminum electrolytic rectifier.

Another peculiar fact is that in the three cases studied the rectified current flows in opposition to the thermoelectric current produced by heating the contact, except in the case of telluriumaluminum at low voltages, as noted above. This was particularly brought to notice by the reversal of the thermoelectric effect in the silicon specimen in which the rectification was reversed. What possible connection there can be between the two facts is, however, difficult to understand.

From the evidence already given it is clear that we are dealing with a contact phenomenon, depending as it does vitally upon the pressure and area of the contact surfaces. When these surfaces are sufficiently large and the contact sufficiently close the rectification entirely disappears. Even if the rectified currents were not opposed in direction to the ordinary thermoelectric currents, their magnitude would seem to preclude the possibility of a thermoelectric explanation. Nevertheless the fact that the direct currents are in general roughly proportional to the square of the alternating currents suggests heat action. 
It may be that there is something of the nature of polarization and a counter electromotive force at the contact, but if this exists no evidence of it has thus far been found.

Of course it is possible that we are here dealing with the still obscure question of the escape of electrons from a conductor and that our rectifying contacts furnish us with conditions under which the electrons pass more readily in one direction than in the other, that is, that it is a case of direct and not secondary rectification.

The rectified currents described have been small but it seems probable that by a proper arrangement of contacts, perhaps in parallel, considerably larger currents could be rectified.

Washington, April 27, igo8. 